\title{
'Resik' sebagai Sistem Informasi untuk Identifikasi Berkas Rekam Medis Ganda di Rumah Sakit Umum Daerah X Daerah Istimewa Yogyakarta
}

\author{
Nuryati ${ }^{1}$, Annisa Maulida Ningtyas², Guntur Budi Herwanto ${ }^{3}$, Widhi Sulistiyo ${ }^{4}$ \\ 1,2Departemen Layanan dan Informasi Kesehatan \\ 3,4Departemen Ilmu Komputer dan Elektronika \\ nur3yati@ugm.ac.id¹, annisamaulidaningtyas@ugm.ac.id², gunturbudi@ugm.ac.id³, \\ widhisulistyo@ugm.ac.id ${ }^{4}$
}

\section{ABSTRAK}

Diajukan 13 November 2019 Diperbaiki 5 Mei 2020 Diterima 5 Mei 2020

Latar Belakang: Di salah satu RSUD X DIY masih terdapat potensi duplikasi nomor rekam medis dan diharapkan untuk segera dilakukan identifikasi untuk menangani masalah tersebut. Diperlukan sebuah mekanisme standar yang digunakan untuk melakukan identifikasi kesamaan data rekam pasien di rumah sakit yang bertujuan untuk menghilangkan duplikasi data rekam medis. Mekanisme tersebut dituangkan dalam sebuah framework untuk mendeteksi duplikasi rekam medis yang diberi nama "RESIK".

Tujuan: Menerapakan framework "RESIK" di salah satu RSUD X DIY untuk mengidentifikasi terjadinya duplikasi rekam medis.

Metode: Metode identifikasi duplikasi rekam medis menggunakan pairwise comparison. Kriteria yang dikomparasikan adalah 100.000 data sosial pasien yang ada pada database SIMRS di RSUD X DIY. Identifikasi potensi duplikasi menggunakan data nomor rekam medis, nama, tanggal lahir, jenis kelamin, dan alamat pasien.

Hasil: Dari 100.000 data sosial pasien, ditemukan bahwa terdapat 413 berkas rekam medis yang terindikasi duplikasi (0,413\%). Dari 413 berkas rekam medis, ditemukan sebanyak 407 pasien $(98,547 \%)$ memiliki dua nomor rekam medis berbeda, 5 pasien $(1,211 \%)$ memiliki 3 nomor rekam medis berbeda, dan 1 pasien $(0,242 \%)$ memiliki empat nomor rekam medis berbeda.

Kesimpulan: Framework "RESIK" terbukti dapat mengidentifikasi adanya duplikasi nomor rekam medis di RSUD X DIY.

Kata Kunci: duplikasi; rekam medis; resik

\section{ABSTRACT}

Background: At one of Regional Hospital in DIY there is still potential for duplicate medical record numbers and it is expected that the identification to solve that problem will be carried out immediately. A standard mechanism is needed to identify the similarity of patient record data in hospitals that aims to eliminate duplication of medical record data. The mechanism is outlined in a framework for detecting duplication of medical records named "RESIK".

Objective: Implement the "RESIK" framework at X DIY Regional Hospital to identify the occurrence of duplicate medical records.

Methods: Identification method of duplicating medical records using pairwise comparison method. Comparable criteria are patient social data from the hospital information system database at X DIY Regional Hospital. Identification of potential duplications using data of medical record number, name, date of birth, gender, and address of the patient.

Results: From 100,000 electronic medical records data found that there were 413 medical record files that indicated duplication (0.413\%). From 413 medical record files, 407 patients $(98,547 \%)$ had two different medical record numbers, 5 patients $(1,211 \%)$ had 3 different medical record numbers, and 1 patient $(0.242 \%)$ had four different medical record numbers.

Conclusion: The "RESIK" Framework is proven to be able to identify duplicate medical record numbers at X DIY Regional Hospital.

Keywords: duplication; medical record; resik 
PENDAHULUAN

Berdasarkan WHO tahun 2004, Sistem Informasi Kesehatan (SIK) didefinisikan sebagai suatu sistem yang digunakan untuk melakukan pengumpulan, pengolahan, pelaporan data, dan penggunaan informasi secara terintegrasi, yang dapat meningkatkan performa layanan, kepuasan pasien, dan menghemat biaya operasional yang harus dikeluarkan oleh fasilitas layanan kesehatan (Shekelle dan Goldzweig, 2009; WHO, 2004). Perkembangan teknologi informasi dan komunikasi khususnya pada bidang kesehatan, memberikan kemudahan dalam penguatan dan pengembangan SIK. Dari tahun ke tahun kebutuhan akan pengembangan SIK di fasilitas pelayanan kesehatan semakin meningkat, hal ini berkesesuaian dengan tujuan yang digalakkan oleh pemerintah, yaitu meningkatkan kualitas, efisiensi dan efektivitas pengelolaan, dan penyelenggaran pembangunan kesehatan dalam pelayanan kesehatan (Kementerian Kesehatan, 2015).

Mengacu pada tujuan tersebut, Pemerintah Daerah mulai mengembangkan SIK yang terintegrasi dan memfasilitasi proses pengumpulan dan pengolahan data yang dapat mendukung peranan SIK dalam pelayanan kesehatan. Sejumlah rumah sakit bahkan telah berinisiatif mengembangkan dan menerapkan sistem elektronik dalam menyelenggarakan Sistem Informasi Manajemen Rumah Sakit (SIMRS) dan Sistem Informasi Puskesmas (SIMPUS) terutama untuk administrasi pendaftaran pasien, administrasi keuangan dan penagihan pasien serta pengolahan data rekam medis pasien, atau dikenal juga dengan manajemen pelayanan rekam medis elektronik.

SIK yang telah dikembangkan dan digunakan pada beberapa fasilitas kesehatan masih memiliki kekurangan. Salah satu kekurangannya adalah masih ditemukannya data duplikasi khususnya untuk berkas rekam medis. Dari hasil kegiatan pengabdian teknologi tepat guna yang dilaksanakan pada Puskesmas Gondokusuman II, diketahui bahwa SIK yang telah diimplementasikan masih ditemukan data seorang pasien yang memiliki banyak nomor rekam medis atau sering disebut dengan duplikasi data rekam medis. Duplikasi rekam medis dalam SIK, merupakan permasalahan yang sering terjadi. Duplikasi rekam medis ini dapat menyebabkan ketidaksinambungan data pasien (Gallagher, 2012; InterSystems, 2015; Karlina et al., 2016). Ketidaksinambungan rekam medis pasien merupakan hal yang harus ditangani, dikarenakan dapat menyebabkan informasi data rekam medis menjadi tidak akurat.

Berdasarkan wawancara dengan Petugas SIK dan Direktur RSUD X DIY, potensi duplikasi nomor rekam medis di RSUD masih ada dan diharapkan untuk segera dilakukan identifikasi. Dari permasalahan tersebut, diperlukan sebuah mekanisme standar yang digunakan untuk melakukan identifikasi kesamaan data rekam pasien di rumah sakit yang bertujuan untuk menghilangkan duplikasi data rekam medis. Mekanisme standar yang akan diterapkan pada penelitian, dituangkan pada sebuah kerangka kerja (framework) yang diberi nama "RESIK". RESIK akan diuji cobakan di Rumah Sakit Umum X DIY dan diharapkan dapat diterapkan di fasilitas kesehatan lainnya.

\section{METODE}

\section{(1) Alat}

Alat penelitian yang digunakan untuk mendukung penelitian ini meliputi sebagai berikut:

A. Perangkat lunak:

1.Sistem Operasi Windows 10

2.XAMPP 5.6.3 dengan PHP Script Language versi 5.6.3

3. phpMyAdmin 4.0.4 dengan Database MySQL 5

4. Editor tools Notepad++

5. Browser Firefox 
'Resik' sebagai Sistem Informasi untuk Identifikasi Berkas Rekam Medis Ganda...

6. Python

B. Perangkat keras:

Laptop yang digunakan untuk proses pengolahan data pada penelitian ini memiliki spesifikasi sebagai berikut:

1. Prosesor Intel Core i5

2. Memori $12 \mathrm{~GB}$

3. Harddisk 1TB HDD

\section{(2) Perancangan sistem}

Bagian ini merupakan penjelasan secara rinci dari langkah perancangan sistem dalam alur penelitian yang dilakukan.

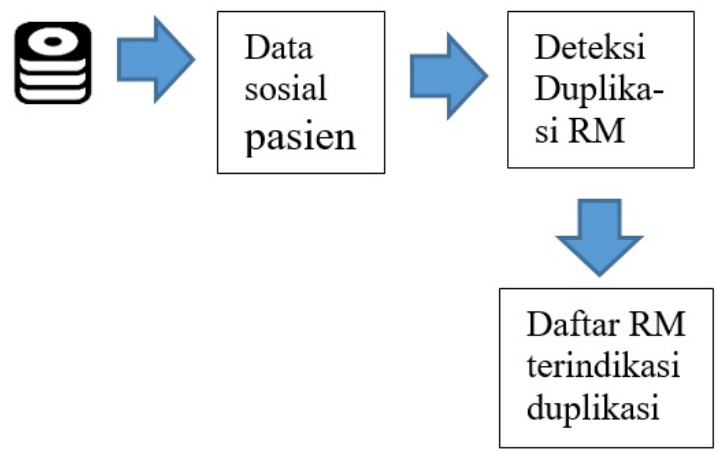

Gambar 1. Workflow sistem.

Data yang digunakan berasal dari basis data SIM RSUD X DIY. Variabel penentu yang digunakan pada proses deteksi duplikasi rekam medis adalah data sosial pasien, yang terdiri dari:

1. Nama pasien,

2. Jenis kelamin,

3. Tanggal lahir pasien,

4. Alamat pasien, dan

5. Nomor rekam rekam medis.

Kelima parameter ini didapatkan dari hasil focus group discussion pada pengabdian yang telah dilakukan.

Setelah didapatkan data sosial tersebut, langkah selanjutnya adalah melakukan proses pendeteksian kesamaan antar pasien, dengan menggunakan metode pair-wise matching.

\section{(3) Pairwise comparison}

Pairwise Comparison adalah metode perbandingan berpasangan yang dapat digunakan untuk memperoleh kecenderungan terkait dari setiap kriteria yang dibandingkan. Dalam hal ini, kriteria yang dibandingkan adalah data sosial pasien yang telah disebutkan sebelumnya. Metode ini akan membandingkan kriteria

setiap pasien dengan pasien lainnya yang ada pada basis data SIMRS. Misalnya, jika basis data SIMRS memiliki 1000 data, maka 1 data akan dibandingkan dengan 999 data lainnya, untuk diperoleh kesamaan data pasien yang terindikasi duplikasi. Misal, pasien 1:

Nama: Alixxx,

Jenis Kelamin: Perempuan

Alamat: Jalan Tentara Pelajar KM. 1 No. 11

Tanggal Lahir: 2-11-1975

No RM: 379xxx

akan dibandingkan dengan pasien 2, 3 dan seterusnya sebanyak data yang terdapat dalam basis data. Dalam contoh pada penelitian ini, pasien 1 akan dibandingkan dengan pasien 2, yang memiliki kriteria:

Nama: Alixxx,

Jenis Kelamin: Perempuan

Alamat: Jalan Tentara Pelajar KM. 1 No. 11

Tanggal Lahir: 2-11-1975

No RM: 357xxx

Dari hasil ilustrasi ditemukan bahwa terdapat kecocokan pada 4 kriteria, yaitu nama, jenis kelamin, alamat, tanggal lahir, tetapi memiliki perbedaan dalam nomor rekam medis, sehingga sistem akan mendeteksi bahwa pasien 1 dengan pasien 2 teridentifikasi merupakan pasien yang sama atau dengan kata lain adalah duplikat. Tabel 1 merupakan ilustrasi metode pairwise comparison.

Tabel 1. Pairwise comparison.

\begin{tabular}{lccccc}
\hline No & & Pasien & Pasien & Pasien & Pasien \\
& & 1 & 2 & 3 & 4 \\
\hline 1 & Pasien 1 & - & similar & - & - \\
2 & Pasien 2 & - & - & - & - \\
3 & Pasien 3 & similar & - & similar & - \\
& & & & & \\
4 & Pasien 4 & - & - & - & similar \\
\hline
\end{tabular}

\section{HASIL DAN PEMBAHASAN}

Identifikasi berkas rekam medis elektronik ganda memanfaatkan data sosial pasien, dengan parameter nama pasien, jenis kelamin, tanggal lahir, alamat, dan nomor rekam medis. Data yang digunakan sebanyak 100.000 data

https://jurnal.ugm.ac.id/jkesvo Published online May 30, 2020 
'Resik' sebagai Sistem Informasi untuk Identifikasi Berkas Rekam Medis Ganda...

berkas rekam medis elektronik. 100.000 data ini di cek kesamaannya dengan menggunakan perangkat lunak 'RESIK' yang telah dikembangkan oleh tim penelitian.

Dari 100.000 data ditemukan bahwa terdapat 413 berkas rekam medis yang terindikasi duplikasi (0,413\%). Dari 413 berkas rekam medis, ditemukan sebanyak 407 pasien $(98,547 \%)$ memiliki dua nomor rekam medis berbeda, 5 pasien $(1,211 \%)$ memiliki tiga nomor rekam medis berbeda, dan 1 pasien $(0,242 \%)$ memiliki empat nomor rekam medis berbeda. Ilustrasi data disajikan dengan melakukan perubahan nama dan kode nomor rekam medis dengan huruf $x$, untuk menjaga kerahasiaan nama pasien. Hal ini dilakukan bahwasanya pasien memiliki hak privasi dan kerahasiaan karena menjadi Hak Asasi serta diatur dalam Undang-undang Nomor 29 Tahun 2004 Tentang Praktik Kedokteran, Undangundang Nomor 36 Tahun 2009 tentang Kesehatan dan Undang-undang Nomor 44 tahun 2009 Tentang Rumah Sakit.

Tabel 2. 50 data berkas rekam medis elektronik terindikasi duplikasi

\begin{tabular}{|c|c|c|c|c|c|c|}
\hline $\mathrm{No}$ & $\begin{array}{c}\text { nama } \\
-1\end{array}$ & $\begin{array}{l}\text { tgl_la } \\
\text { hir_1 }\end{array}$ & $\begin{array}{l}\text { No_r } \\
\text { ekam } \\
\text {-med } \\
\text { is1 }\end{array}$ & $\begin{array}{c}\text { nama } \\
\_2\end{array}$ & $\begin{array}{c}\text { tgl_l } \\
\text { ahir_ } \\
2\end{array}$ & $\begin{array}{l}\text { no_re } \\
\text { kam_- } \\
\text { medis } \\
\text { _2 }\end{array}$ \\
\hline 1 & $\begin{array}{l}\text { ADA } \\
M x x x\end{array}$ & $\begin{array}{l}10 / 21 / \\
07\end{array}$ & $\begin{array}{l}3 \times x 5 \\
3\end{array}$ & $\begin{array}{l}\text { ADA } \\
M x x x\end{array}$ & $\begin{array}{l}10 / 21 \\
/ 07\end{array}$ & $\begin{array}{l}3 x x \\
4\end{array}$ \\
\hline 2 & $\begin{array}{l}\text { ADI } \\
x \times x\end{array}$ & $\begin{array}{l}10 / 10 / \\
91\end{array}$ & $\begin{array}{l}3 \times x x x \\
65\end{array}$ & $\begin{array}{l}\text { ADI } \\
x \times x\end{array}$ & $\begin{array}{l}10 / 10 \\
/ 91\end{array}$ & $\begin{array}{l}3 \times x \times 5 \\
5\end{array}$ \\
\hline 3 & $\begin{array}{l}\text { ADIT } \\
x x x\end{array}$ & $\begin{array}{l}08 / 19 / \\
89\end{array}$ & $\begin{array}{l}3 \times x x \\
84\end{array}$ & $\begin{array}{l}\text { ADIT } \\
x x x\end{array}$ & $\begin{array}{l}08 / 19 \\
/ 89\end{array}$ & $\begin{array}{l}40 x x x \\
39\end{array}$ \\
\hline 4 & $\begin{array}{l}\text { ALIxx } \\
x\end{array}$ & $\begin{array}{l}11 / 02 / \\
75\end{array}$ & $\begin{array}{l}3 \times x x \\
016\end{array}$ & $\begin{array}{l}\text { ALIxx } \\
x\end{array}$ & $\begin{array}{l}11 / 02 \\
/ 75\end{array}$ & $\begin{array}{l}3 \times x \times 4 \\
9\end{array}$ \\
\hline 5 & $\begin{array}{l}\text { ALIxx } \\
x\end{array}$ & $\begin{array}{l}11 / 02 / \\
75\end{array}$ & $\begin{array}{l}3 \times x x \\
49\end{array}$ & $\begin{array}{l}\text { ALIxx } \\
x\end{array}$ & $\begin{array}{l}11 / 02 \\
/ 75\end{array}$ & $\begin{array}{l}4 \times x \times 5 \\
3\end{array}$ \\
\hline 6 & $\begin{array}{l}\text { ALIxx } \\
x\end{array}$ & $\begin{array}{l}09 / 19 / \\
02\end{array}$ & $\begin{array}{l}3 \times x x \\
68\end{array}$ & $\begin{array}{l}\text { ALIxx } \\
x\end{array}$ & $\begin{array}{l}09 / 19 \\
/ 02\end{array}$ & $\begin{array}{l}3 \times x \times 7 \\
8\end{array}$ \\
\hline 7 & $\begin{array}{l}\text { ANA } \\
x x x\end{array}$ & $\begin{array}{l}06 / 27 / \\
79\end{array}$ & $\begin{array}{l}\text { 0xxx } \\
05\end{array}$ & $\begin{array}{l}\text { ANA } \\
x x x\end{array}$ & $\begin{array}{l}06 / 27 \\
/ 79\end{array}$ & $\begin{array}{l}3 x \times x 2 \\
6\end{array}$ \\
\hline 8 & $\begin{array}{l}\text { BASx } \\
x x\end{array}$ & $\begin{array}{l}08 / 15 / \\
57\end{array}$ & $\begin{array}{l}2 x x x \\
20\end{array}$ & $\begin{array}{l}\text { BASx } \\
x x\end{array}$ & $\begin{array}{l}08 / 15 \\
/ 57\end{array}$ & $\begin{array}{l}3 \times x \times 5 \\
9\end{array}$ \\
\hline 9 & $\begin{array}{l}\text { BASx } \\
x x\end{array}$ & $\begin{array}{l}08 / 15 / \\
57\end{array}$ & $\begin{array}{l}3 x x x \\
59\end{array}$ & $\begin{array}{l}\text { BASx } \\
x x\end{array}$ & $\begin{array}{l}08 / 15 \\
/ 57\end{array}$ & $\begin{array}{l}3 \times x \times 7 \\
8\end{array}$ \\
\hline 10 & $\begin{array}{l}\text { DEWI } \\
x \times x\end{array}$ & $\begin{array}{l}10 / 21 / \\
84\end{array}$ & $\begin{array}{l}3 \times x x \\
36\end{array}$ & $\begin{array}{l}\text { DEWI } \\
x \times x\end{array}$ & $\begin{array}{l}10 / 21 \\
/ 84\end{array}$ & $\begin{array}{l}3 \times x \times 1 \\
6\end{array}$ \\
\hline
\end{tabular}

Duplikasi berkas rekam medis yang ditemukan adalah satu orang pasien memiliki lebih dari satu berkas rekam medis. Pada hasil penelitian ini, lebih banyak ditemukan bahwa 1 pasien memiliki 2 nomor rekam medis, namun ditemukan juga beberapa data dimana pasien memiliki 3 nomor rekam medis.

Hal ini sesuai dengan hasil peneltian Hasibuan bahwa dari 720 berkas rekam medis, sebanyak $1.45 \%$ berkas rekam medis yang memiliki nomor ganda (Hasibuan, 2019). Penelitian lain yang dilakukan oleh Karlina et al., (2016) dihasilkan bahwa penyebab dari $8,44 \%$ kejadian duplikasi nomor rekam medis di Puskesmas Adipala adalah tidak adanya regulasi yang digunakan pada sistem penyimpanan.

Duplikasi berkas rekam medis ini dapat disebabkan oleh beberapa faktor. Salah satu penyebab yang paling umum adalah kesalahan yang terjadi pada proses pendaftaran pasien. Misalnya, di bagian Unit Gawat Darurat (UGD) datang seorang pasien yang tidak sadarkan diri dan tidak membawa kartu identitas, sehingga petugas pendaftaran dibagian UGD tidak dapat menginputkan data secara akurat. Hal ini sesuai dengan hasil penelitian dari Muldiana (2016), Olla (2016), dan Kurniasih (2015) bahwa duplikasi penomoran umumnya disebabkan oleh proses identifikasi yang kurang tepat dan dilaksanakan secara manual sehingga menyebabkan seorang pasien mendapat lebih dari satu nomor rekam medis (Kurniasih et al., 2015; Muldiana, 2016; Olla, 2016).

Contoh lainnya adalah jika seorang pasien sudah berpindah alamat, tetapi ketika berkunjung untuk berobat kembali, pasien tersebut tidak menginfokan perubahan alamat, sehingga ketika proses pencarian data yang dilakukan oleh petugas dapat menyebabkan petugas tersebut tidak melakukan pengecekan hasil pencarian secara teliti.

Kasus yang lain berdasarkan penelitian Fernandes et al., yakni adanya 
'Resik' sebagai Sistem Informasi untuk Identifikasi Berkas Rekam Medis Ganda...

potensi kesalahan pengambilan data pasien jika sebuah rumah sakit beralih kepada sistem rekam medis elektronik, sedangkan sebelumnya ditemukan adanya duplikasi pada penyelenggaraan rekam medis manual (Fernandes et al., 2001). Adanya duplikasi rekam medis dapat mengakibatkan waktu yang lama dalam pencarian berkas rekam medis, serta sebagai upaya pencegahan maka diperlukan adanya penegakkan prosedur identifikasi pasien (Davis dan LaCour, 2016).

Petugas pendaftaran memiliki peran dan tanggung jawab untuk memvalidasi data pasien yang berkunjung di rumah sakit untuk dapat memastikan datanya benar dan secara akurat memasukan informasi pasien pada proses pendaftaran. Apabila penomoran rekam medis dilakukan secara manual, pada saat pasien tidak membawa kartu berobat, jika petugas tidak menemukan nomor rekam medis pada buku register penomoran, akan dibuatkan berkas rekam medis baru dengan nomor baru (Gunarti et al., 2016). Data yang tidak akurat seperti nomor rekam medis ganda, dapat mengakibatkan lamanya proses pencarian berkas rekam medis oleh petugas filing (Mardyawati dan Akhmadi, 2016).

Penyebab masih terjadinya duplikasi berkas rekam medis ini juga tidak hanya disebabkan oleh kesalahan manusia (Olla, 2016). Kesalahan dalam mengidentifikasi nama, mengeja nama, dan petugas tidak melakukan penyisiran berkas yang memiliki nomor berbeda untuk satu pasien, jika ditemukan nomor ganda, petugas tidak melakukan penggabungan berkas rekam medis juga berperan sebagai penyebab. (Nurmawati dan Arofah, 2019). Duplikasi berkas rekam medis elektronik ini juga dapat disebabkan karena sistem informasi yang sudah dikembangkan dan diterapkan belum memiliki algoritma yang dapat mendeteksi adanya indikasi duplikasi data secara otomatis, ketika proses pencarian dilakukan oleh petugas.
Kemudian, jika dilihat dari stuktur basis data pada sistem informasi kesehatan yang terdapat di RSUD, dapat diketahui bahwa sistem informasi kesehatan ini belum menjadikan NIK sebagai pembeda yang unik untuk setiap data pasien. Pembeda kunci pada basis data SIMRS ini adalah nomor rekam medis, jika sistem ingin mendapatkan data informasi pasien yang unik dan dapat dibedakan antara satu pasien dengan pasien lainnya adalah dengan memanfaatkan NIK.

Sebagaimana kita ketahui, bahwa NIK adalah nomor identitas penduduk yang memiliki sifat yang unik, tunggal serta melekat pada seseorang yang terdaftar sebagai penduduk Indonesia. NIK ini berlaku seumur hidup dan selamanya yang diberikan oleh pemerintah dan diterbitkan oleh instansi pelaksana kepada setiap penduduk setelah dilakukan pencatatan biodata. NIK ini memiliki peran penting dalam pencegahan duplikasi pada SIMRS.

Berdasarkan hasil analisis yang dilakukan dapat diambil kesimpulan bahwa RESIK mampu mengidentifikasi data berkas rekam medis terindikasi duplikasi sebanyak 413 data dari 100.000 data berkas rekam medis elektronik yang dijadikan sampel penelitian.

Berdasarkan Fernandes et al., upaya koreksi dari duplikasi berkas rekam medis adalah dengan cara menggabungkan menjadi satu data pasien (Fernandes et al., 2001). Upaya lainnya dapat menggunakan aplikasi RFID (Radio Frequency Identification) dalam layanan pencatatan dan registrasi pasien, sehingga dapat meminimalisir kejadian kesalahan penulisan nomor rekam medis (Olla, 2016).

\section{PENUTUP}

Dari 100.000 berkas rekam medis elekrtronis yang dijadikan sampel penelitian ditemukan 413 data rekam medis elektronis yang terindikasi duplikasi. Duplikasi rekam medis ini 
'Resik' sebagai Sistem Informasi untuk Identifikasi Berkas Rekam Medis Ganda...

terjadi dikarenakan kesalahan umum yang dilakukan pada proses pendaftaran, dan disebabkan karena belum adanya algoritma yang dapat mendeteksi duplikasi.

\section{DAFTAR PUSTAKA}

Davis, N., \& LaCour, M. (2016). Foundation of Health Information Management (4th ed.). $\quad$ Elsevier. https:// www.elsevier.com/books/ foundations-of-health-informationmanagement/davis/978-0-323-37811-6

Fernandes, L., Lenson, C., Hewitt, J., Weber, J., \& Yamamoto, J. A. (2001). Medical Record Number Errors: A Cost of Doing Business? https:// www.academia.edu/7410828/

Medical_Record_Number_Errors_A_ Cost_of_Doing_Business

Gunarti, R., Abidin, Z., Qiftiah, M., \& Bahruddin. (2016). Tinjauan Pelaksanaan Family Folder Untuk Rekam Medis Rawat Jalan di Puskesmas Guntung Payung Tahun 2016. Jurkessia, VI(3), 46-54. http:// journal.stikeshb.ac.id/index.php/ jurkessia/article/view/74/72

Hansard, L. W. (2013). The Risk of Duplicate Patient Records; Gallagher Healthcare Practice. Arthur J. Gallagher\& Co. https://www.lorman.com/resources/ whitepaper-the-risk-of-duplicatepatient-records-109411WP

Hasibuan, A. S. (2019). Faktor - Faktor Yang Menyebabkan Terjadinya Duplikasi Penomoran Berkas Rekam Medis Rumah Sakit Umum Imelda Pekerja Indonesia Medan Tahun 2016. Jurnal Ilmiah Perekam Dan Informasi Kesehatan Imelda, 1(2), 104-110. http:// jurnal.uimedan.ac.id/index.php/ JIPIKI/article/view/18

InterSystems. (2016). Impact of Mismatched Patient Records Infograph. InterSystems Corporation. http:// www.intersystems.com/wp-content/ uploads/
Impact_of_Mismatched_Patient_Reco rds_Infograph.pdf

Karlina, D., Putri, I. A., \& Santoso, D. B. (2016). Kejadian Misfile dan Duplikasi Berkas Rekam Medis Sebagai Pemicu Ketidaksinambungan Data Rekam Medis. Jurnal Kesehatan Vokasional, 1(1), 44. https://doi.org/10.22146/ jkesvo.27477

Kementerian Kesehatan. (2015). Peraturan Menteri Kesehatan Nomor 97 Tahun 2015.

Kurniasih, S., Ambarwati, L., \& Wikusna, W. (2015). Aplikasi Pelayanan Kesehatan Ibu dan Anak (KIA) di Puskesmas Cinunuk. Jurnal Teknologi Informasi, 2(3), 92-96. http:// journals.telkomuniversity.ac.id/jti/ article/view/511

Mardyawati, E., \& Akhmadi, A. (2016). Pelaksanaan Sistem Penyimpanan Rekam Medis Family Folder di Puskesmas Bayan Lombok Utara. Jurnal Kesehatan Vokasional, 1(1), 27. https://doi.org/10.22146/jkesvo.27474

Muldiana, I. (2016). Analisis Faktor-Faktor Yang Mempengaruhi Duplikasi Penomoran Rekam Medis Di Rumah Sakit Atma Jaya 2016. Jurnal INOHIM (Indonesian of Health Information Management), 4(2), 48-53. https:// inohim.esaunggul.ac.id/index.php/ INO/article/view/148/128

Nurmawati, I., \& Arofah, K. (2019). Analisis Aspek Kompetensi Individu Dalam Duplikasi Nomor Rekam Medis di Puskesmas. J-REMI: Jurnal Rekam Medik Dan Informasi Kesehatan, 1(1). https://publikasi.polije.ac.id/ index.php/j-remi/article/view/ $1928 / 1313$

Olla, P. K. (2016). Pemanfaatan Teknologi RFID (Radio Frequency Identification) Dalam Layanan Registrasi Rekam Medis Pasien. Simetris: Jurnal Teknik Mesin, Elektro Dan Ilmu Komputer, 7(1), 241. https://doi.org/10.24176/ simet.v7i1.510 
'Resik' sebagai Sistem Informasi untuk Identifikasi Berkas Rekam Medis Ganda...

Shekelle, P. G., Morton, S. C., \& Keeler, E. B. (2006). Costs and Benefits of Health Information Technology. In Evidence report/technology assessment (Issue 132). https://doi.org/10.23970/ AHRQEPCERTA132
WHO. (2004). Developing Health Management Information Systems - a Practical Guide for Developing Countries. In https://iris.wpro.who.int/ handle/10665.1/5498. WHO Regional Office for the Western Pacific. https:// iris.wpro.who.int/handle/ 10665.1/5498 